\title{
MECHATRONIC BASED ENERGY MANAGEMENT AND AUTOMATION SYSTEM FOR AGRO INDUSTRIES
}

\author{
Nagala Theja ${ }^{1}$, M Giriraj ${ }^{2}$ \\ ${ }^{1}$ Pursuing M.Tech in Mechatronics, VIT University, Vellore, India \\ ${ }^{2}$ Assistant Professor, Department of Mechatronics, SMBS, VIT University, Vellore, India
}

\begin{abstract}
The main aim of this paper is to develop an automation system with energy management capability for agro-based industries using sensors and ZigBee technology. To design an automation system which will monitor the analog parameters and to send these values to the control system where they can be read and control with the set points. If these values exceed their set points, the system will start the controlling devices and set back the exceeded values back to normal. It combines energy management with energy transfer, during power failure by using external batteries. Here ZigBee used to communicate the data wirelessly. The analog parameters like Soil Moisture, Water Level, Temperature, and current flow are measured by the respective sensors and these values are transmitted by the transmitter node. The receiver section is connected to host computer. The PIC based microcontroller receives these values and compares these values with the fixed values and if they exceed the set points, the PIC controller will send commands to controlling devices which will corrects the exceeded values to normal.
\end{abstract}

Keywords: Automation, Energy Management, Moisture Sensor, Level Sensing

\section{INTRODUCTION}

Advances in mechatronics technology and in wireless sensor networks have made owning and operating the agro-based industries like Greenhouse, Floriculture, Horticulture, Residential Gardening, and Landscape etc. easier than ever before. Innovations in mechatronics systems can aid the workers in the agro industries by automatically adjusting temperature, humidity, and light intensity within the industry or from a remote location. An automatic control system will improve plant life within the agro industry by providing the suitable condition for plant growth and to producing a more uniform product.

Industrial Automation Systems can adjust temperature, adjust humidity and control Light intensity. Greenhouse accessories that were controlled by using industrial automation systems are fans, vents, moisture control systems, heating and cooling systems.

\section{EXISTING SYSTEM}

In olden methods, the industrial parameters are monitored through individual LCD displays. With the help of various sensors, the parameters are sensed and the values are processed by the microcontrollers. Then, the processed values are displayed in the individual LCD displays which are connected to the microcontrollers. For monitoring the parameters in various locations, the individual microcontrollers and LCD displays are required. In case, the sensed parameter value exceeds certain value at the instant of monitoring, the control process will be held by the workers of the industry.
Because of monitoring the industrial parameters through individual parameters through individual LCD displays, this method requires more manual power to monitor them continuously.

\section{PROPOSED SYSTEM}

The functional block diagram of the proposed system is given in Figure 1. The sensors are used to monitors the parameters such as soil moisture, water level in the tank and current flow in the industry. The monitoring data from sensors is continuously fed to the PIC microcontroller. The microcontroller is programmed to monitoring these parameters of the industry were come out of the desired values or crosses the safety limit. Then microcontroller generates the control signal to bring back the control parameters to the desired values. All the sensors data and microcontroller data are interconnected to personal computer through ZigBee. A keypad is used to set the desired values of the industry to the microcontroller. 


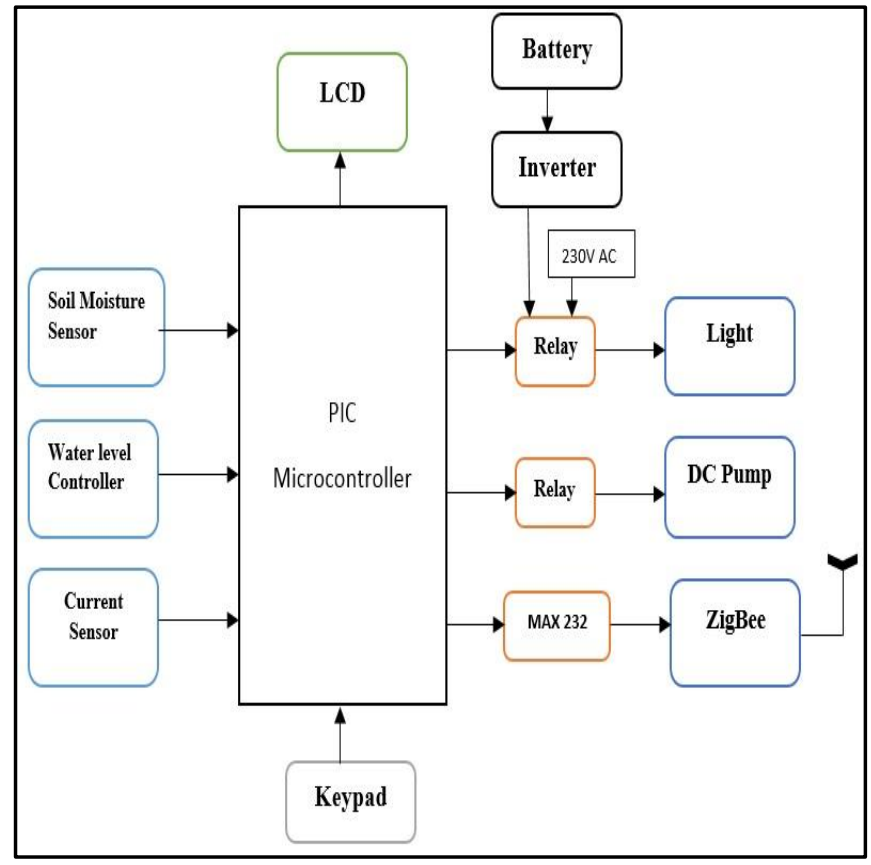

Fig 1. Functional Block Diagram

By using a soil moisture sensor, we are going to continuously monitoring the moisture level in the soil by inserting the soil moisture sensor probes at multiple depths. By using the sensor data we can maximize the potential yield, saves water by only irrigating when needed and saves energy by lower pumping costs. The soil moisture sensor along with the amplifier circuit is shown the Figure 2. The soil moisture sensor output is fed to microcontroller.

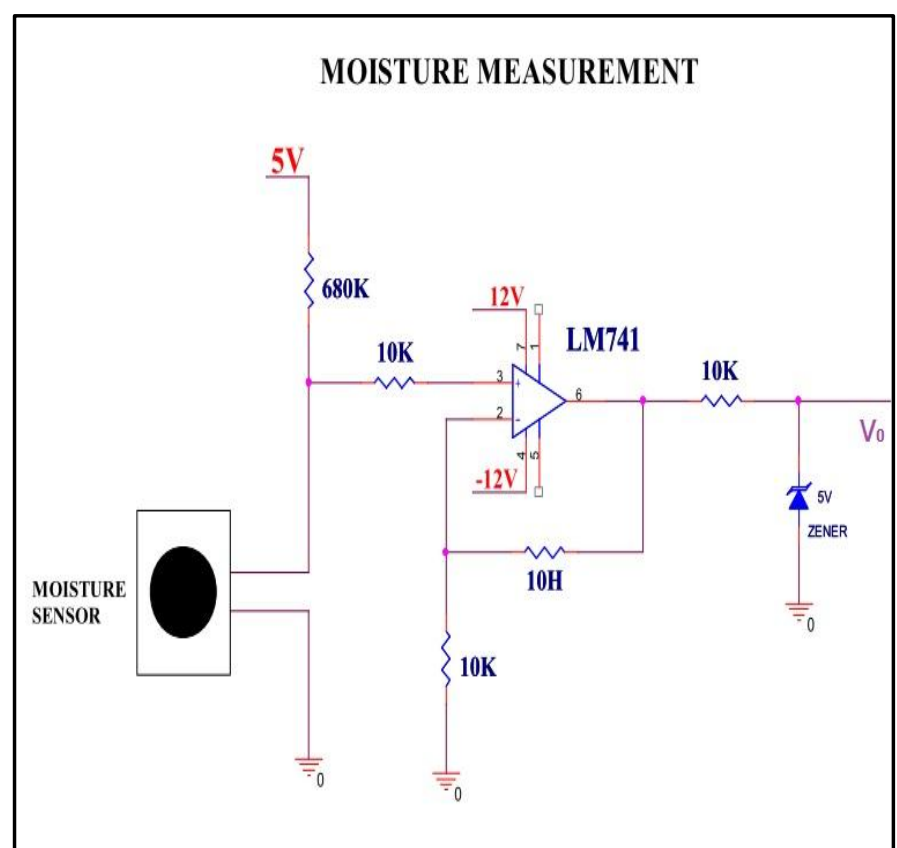

Fig 2. Soil moisture sensor with amplifier circuit

A level sensor with float switch is used to sense the either raising or falling of water level in the water tank. The output of this sensor is used to control the water pump switch using the microcontroller. The water level sensor with amplifier circuit is shown in the Figure 3.

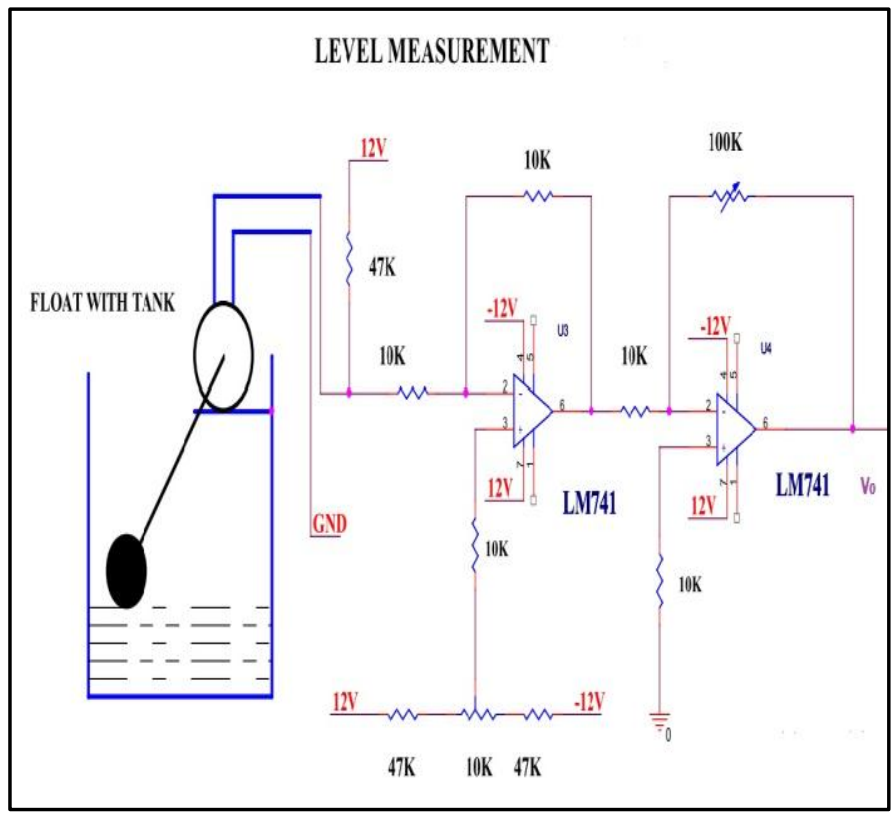

Fig 3. Water level controller circuit

Energy management in agro industry is done by using a relay driving circuit, external battery and inverter circuit. During normal conditions the power is supplied to the output devices using relay driving circuit connected load and microcontroller.

During power failure conditions sensed by using current sensor connected to the microcontroller, then energy to output devices using an external battery and inverter circuit. The figures of the above conditions are shown in Figure 4.and Figure 5.

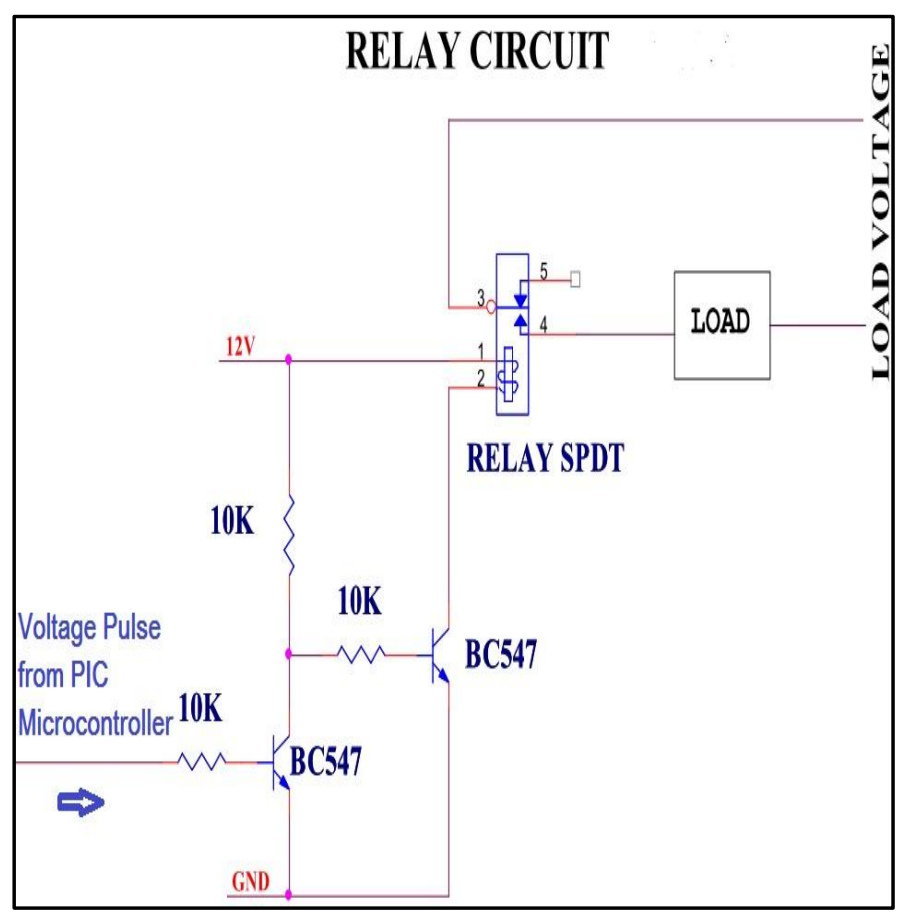

Fig 4 Power supply circuit during normal conditions 


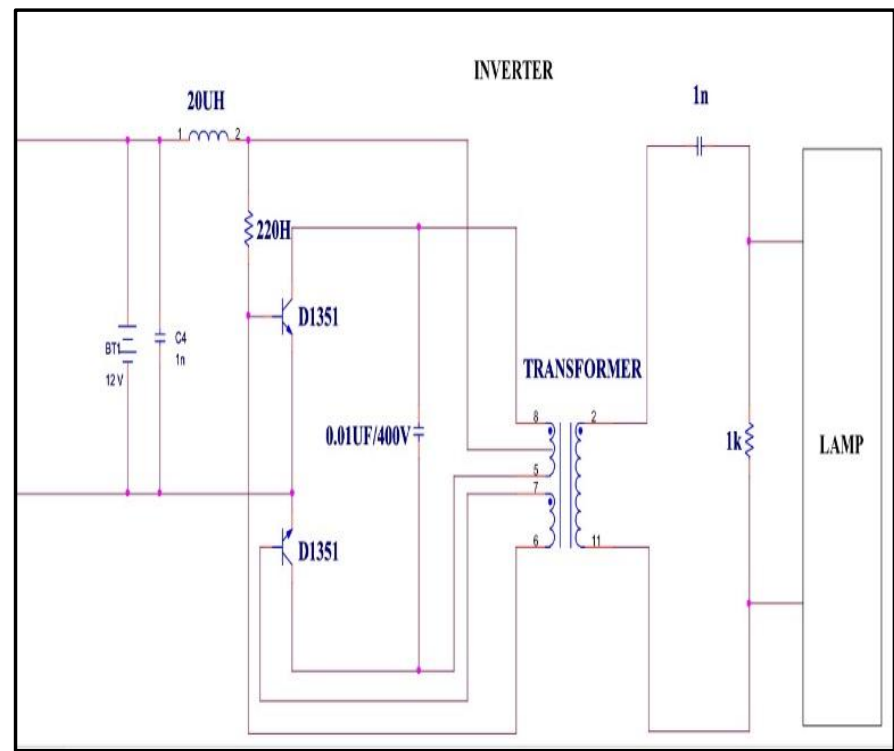

Fig 5. Power supply circuit from relay circuit to Lamp during power failure condition

\section{HARDWARE CIRCUIT}

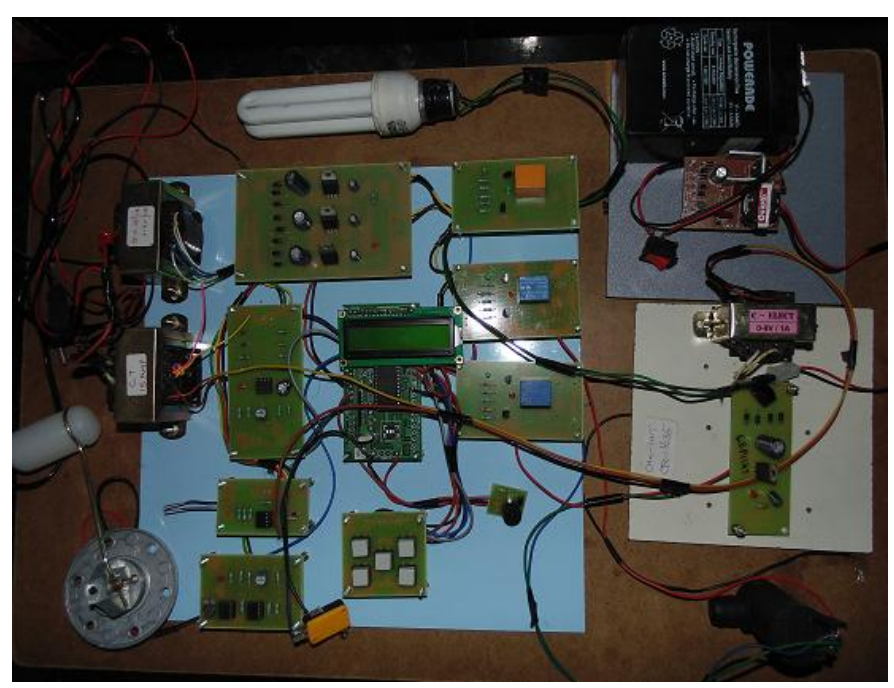

Fig 6. Hardware Circuit Diagram

\section{SOFTWARE CONTROL FLOW DESIGN}

The PIC microcontroller is programmed to perform the following tasks:

- Collect data from sensors

- Data analysis and generating control signals

- Display data

- $\quad$ Sending control signals to systems

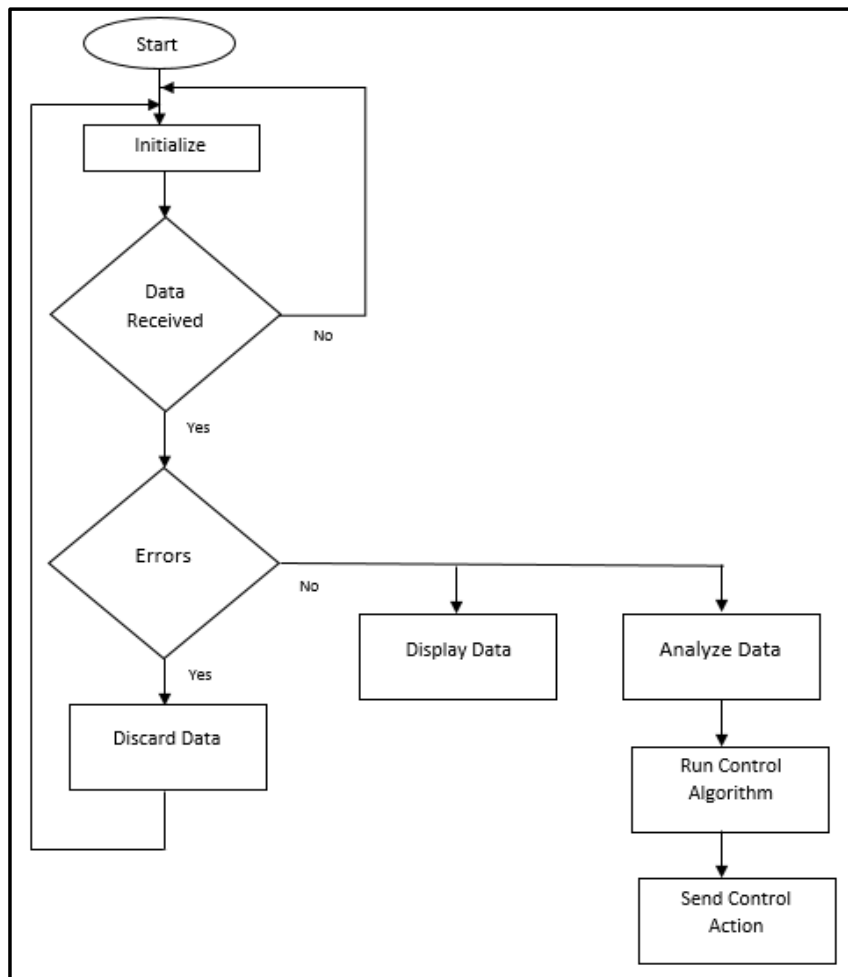

Fig 7. Microcontroller software flow diagram

\section{RESULTS AND DISCUSSIONS}

All the results obtained during the monitoring and controlling the different parameters of the Agro industry using the developed system were shown in the Figure 8.

In the first stage after setting the required moisture level using the keypad, the developed system checks the status of different parameters of the industry such water level, moisture level and load conditions the developed system generates the required control signals to ON/OFF the pump and battery management system to bring back the control parameters to their normal range and the results displayed on the LCD display.

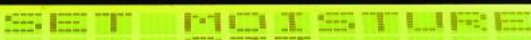
$x=-1+1=$

IX- \#

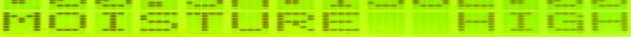

1-:

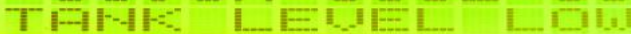

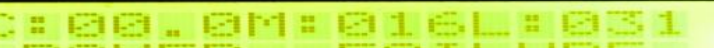

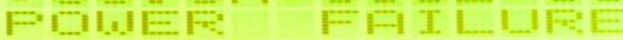

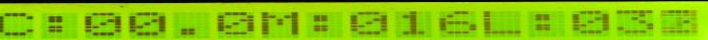

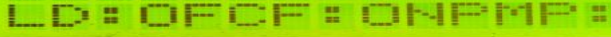

L

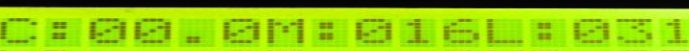
$\Gamma_{i} \equiv$

Fig 8. Results displayed on LCD 


\section{CONCLUSION}

The developed automation and energy system can monitors and controls the different parameters in an agro-based industries such as soil moisture levels, water level in the water tanks, light intensity and energy management without the human intervention there by reducing the number of workers required and increases the productivity of the industry by reducing the mistakes occurred due to manual monitoring of different parameters.

\section{REFERENCES}

[1]. P Hanswal, O Dale, D Gupta, R.N Yadav "Designing a Central Control Unit and Soil Moisture Sensor Based Irrigation Water Pump System”, IEEE, Texas Instruments India Educator's Conference (TIIEC), April 2013.

[2]. Zhang Lihong, Sun Lei, Han Shufen, Lu Weina "Measurement and Control System of Soil Moisture of Large Greenhouse Group Based on Double CAN Bus", IEEE, Third International Conference on Measuring Technology and Mechatronics Automation (ICMTMA), Vol. 2, 2011.

[3]. Ning An, Yu An “A water level-controller for green house sump tank”, IEEE, Second International Conference on Mechanic Automation and Control Engineering (MACE), July, 2011.

[4]. S.D Smitha, J.S Savier, F.M Chacko "Intelligent control system for efficient energy management system in commercial buildings", IEEE, Annual Internal Conference on Emerging Research Areas (AICERA), June 2013.

[5]. Chandini Anand, Shashikanth Sadistap, Satish Bindal, B.A. Botre, KSN Rao "Wireless multi sensor embedded system for Agro-industrial monitoring and control", International Journal on Advances in Networks and Services, Vol. 3, 2010.

\section{BIOGRAPHIES}

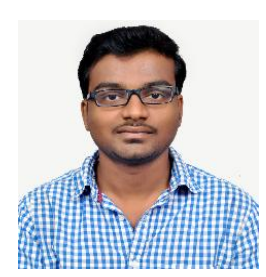

Nagala Theja is pursuing his M.Tech in Mechatronics from VIT University, Vellore and his areas of interest include Mechatronics and Embedded Systems.

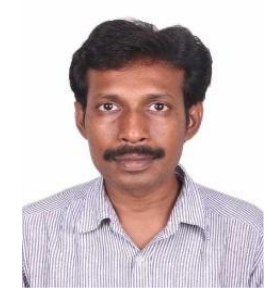

Mannayee Giriraj is working as an assistant professor in Mechatronics Division, School of Mechanical and Building Sciences, VIT University, Vellore. His areas of interests include Mechatronics, Cloud computing and Automation. 